\title{
Extraction cost of quality and testing in software project
}

\begin{abstract}
Implementation of quality and testing by outsourced test team is new field procurement in software project especially in software development. In Government Agency of Malaysia, cost procurement for implementing both of the quality and testing are blended together with the cost of overall project which is implemented by software development team. Therefore, the cost of quality and testing has to extract from the overall cost of software project. The problem is how to estimate the cost of quality and testing that will be provided to outsourced test team. This paper aim to extract the cost of quality and testing from the total cost of the software project based on Salleh and Primandaria model. The result shows that our extraction model produces an acceptable estimation for project and suitable apply by Government Agency of Malaysia.
\end{abstract}

Keyword: Software testing; Software cost estimation; Function point; COCOMO; Linear regression 